\title{
Antimicrobial prophylaxis and post-chemotherapy neutropenic fever in patients with leukemia: comparisons of C-reactive protein, procalcitonin and immediate fever outcome measures between those with and without prophylaxis, and the implications for practice
}

\author{
Choi Wan Chan ${ }^{1}$ (D) Alex Molassiotis ${ }^{1} \cdot$ Harold K. K. Lee ${ }^{2}$
}

Received: 14 January 2021 / Accepted: 28 May 2021 / Published online: 8 June 2021

(c) The Author(s) 2021

\begin{abstract}
Purpose The efficacy of prophylactic antimicrobial treatment renders challenges in patients with leukemias receiving chemotherapy. The study aimed to compare differences in C-reactive protein (CRP) and procalcitonin (PCT) at presentation and the immediate outcome measures of post-chemotherapy NF between patients with and without antimicrobial prophylaxis. Methods A 5-year observational study included $282 \mathrm{NF}$ episodes in 133 leukemia patients requiring hospital care from January 2014 to May 2019. We collected demographic characteristics, laboratory data of blood cell counts and inflammatory biomarkers, and immediate outcome measures of NF, including microbiologically diagnosed infections, presence of predominant pathogens, required modification of antibiotics during NF, adverse medical complications, total fever duration, and deaths. We evaluated data between patients with and without prophylaxis.

Results Of patients, $77.3 \%, 68.4 \%$, and $20.6 \%$ had antibiotic prophylaxis, antifungal prophylaxis, and no prophylaxis, respectively. There were totally 15 deaths -13 with antibiotic prophylaxis and 10 with antifungal prophylaxis. CRP, PCT, and immediate outcome measures of NF did not show significant differences between those with and without antimicrobial prophylaxis. Although between-group differences showed no statistical significance, higher median fever duration, CRP and PTC values, and higher proportions of NF requiring modification of antibiotics were found more frequently in those with antimicrobial prophylaxis than in those without.

Conclusion The benefits of using antimicrobial prophylaxis were less supported. Enhancing diagnostic laboratory and medical complication surveillance and periodic evaluation of institutional data during post-chemotherapy neutropenia and NF in relation to antimicrobial prophylaxis is promising in providing insights to redefine the risk-benefit accounts of using prophylaxis.
\end{abstract}

Keywords Leukemia - Post-chemotherapy neutropenic fever · Antibiotic or antifungal prophylaxis · C-reactive protein ·

Procalcitonin $\cdot$ Risk-benefit of prophylaxis

\section{Introduction}

Post-chemotherapy immunocompromised hematological patients are at risk of bacterial and fungal infections. Leukemias constitute a large proportion of hematological

Choi Wan Chan

cw.chan@polyu.edu.hk

1 School of Nursing, The Hong Kong Polytechnic University, Hung Hom, Kowloon, Hong Kong

2 Department of Medicine and Geriatrics, Princess Margaret Hospital, Kowloon, Hong Kong malignancies. It is common for neutropenic patients with leukemias to receive antimicrobial prophylactic treatments in post-chemotherapy. Antibiotic prophylaxis for high-risk patients with prolonged duration of neutropenia has been recommended in international guidelines [1-5]. A systematic review showed that antibiotic prophylaxis in post-chemotherapy afebrile neutropenic patients significantly reduced the occurrence of fever, indicators of infection, microbiologically documented infections, and infection-related and all-cause mortality [6].

In a randomized study, patients with hematological malignancies who developed neutropenic fever while on 
antibiotic prophylaxis had a lower probability of response to first-line empirical antibiotic treatments and a delay in fever resolution compared with those randomized to no prophylaxis, and there was no reduction in hospital stays and cost among those receiving prophylaxis when compared to those without [7]. There is also considerable literature showing that the emergence of antimicrobial resistance and the spread of multidrug-resistant pathogens are associated with the use of antibiotic prophylaxis [8-11]. Putting the extensive use of prophylaxis in the context of increasing antibiotic resistance, Australian guidelines advise against the routine use of prophylaxis for neutropenia [12]. In view of the pharmacovigilance reports, the U.S. Food and Drug Administration has attended to the issue of antibiotic toxicity and released warnings against unnecessary use of antibiotics due to their association with disabling and potentially permanent side effects that involve the central nervous system, nerves, peripheral neuropathy, muscles, joints, tendinitis, tendon rupture, confusion, and hallucinations [13]. Investigators have even drawn attention to the fact that the potential benefit of prophylaxis in lowering the rate of infection was demonstrated in regions with low to moderate antibiotic resistance rates, suggesting that it might not be applicable in regions with a high prevalence of resistant pathogens [14-16]. Therefore, a clear-cut benefit regarding the efficacy of antibiotic prophylaxis appears less assured.

Candida spp. and Aspergillus spp. account for most of the fungal infections occurring during neutropenia in patients with hematological malignancy (HM) [17]. Although antifungal prophylaxis is used against Candida spp., Aspergillus has surpassed Candida as a cause of invasive fungal infections [18]. Antifungal therapy reducing the diagnostic sensitivity of a galactomannan enzyme immunoassay for fungal infection has also been reported [19]. As such, these offer challenges in prophylactic antifungal therapy, confirming that the use of prophylaxis might have an impact on the choice of strategy in the management of post-chemotherapy neutropenia [20].

Local policies on the use of antimicrobial prophylaxis are often in line with international antimicrobial stewardship programs. It is essential that specialists and clinicians examine the impact of antimicrobial prophylaxis that is apparently suggested [21]. Institutional research data analyses and clinical investigations of antimicrobial prophylaxis in post-chemotherapy NF are useful to inform policies and practices, but these appear rarely. The purpose of the present study was to examine the impact of antimicrobial prophylaxis in post-chemotherapy NF in leukemias by comparing differences in inflammatory biomarkers of $\mathrm{C}$-reactive protein (CRP) and procalcitonin (PCT) at the onset of NF and immediate outcome measures of NF between those with and without prophylaxis. CRP and PTC have been widely studied as inflammatory biomarkers related to NF [22-24].

\section{Methods}

\section{Sample, design, and definition of an NF episode}

The study was part of a larger university and institutional review board-approved observational study investigating clinical profiles and patient-reported symptoms and their relationships with inflammatory biomarkers and clinical prognostic data in post-chemotherapy NF patients with hematological malignancies. The present study included data from adult patients with leukemias (acute/chronic myeloid leukemia (AML and CML) and lymphocytic leukemia (ALL and CLL)), admitted between January 2014 and May 2019 requiring clinical care for post-chemotherapy NF in the hematological units of a regional acute hospital. Febrile episodes were identified retrospectively and prospectively from January 2014 to December 2016 and June 2017 to May 2019, respectively. Informed consent was obtained from participants for the prospective collection of data. We used the same study pro forma to collect and retrieve data from the patient medical records for both groups. The inclusion criteria consisted of patients $\geq 18$ years, diagnosed with leukemias and presenting with an episode of NF. Fever and neutropenia were defined as a temperature $\geq 38.3{ }^{\circ} \mathrm{C}$, or $\geq 38{ }^{\circ} \mathrm{C}$ for two episodes more than $1 \mathrm{~h}$ apart, and an absolute neutrophil count $(\mathrm{ANC})<0.5 \times 10^{9}$ cells $/ \mathrm{L}$, or $<1 \times 10^{9}$ cells $/ \mathrm{L}$, expected to decrease below $0.5 \times 10^{9}$ cells $/ \mathrm{L}$ within $48 \mathrm{~h}$ [25]. We defined an NF episode as the duration from the onset of NF to the point of NF subsiding (i.e., $<37.5^{\circ} \mathrm{C}$ ), provided that the temperature to which it subsided (i.e., $<37.5{ }^{\circ} \mathrm{C}$ ) was persistent for $48 \mathrm{~h}$ (a time point of 48-h afebrile). An afebrile temperature was defined as a temperature $\leq 37.4{ }^{\circ} \mathrm{C}$. Subsequent episodes of fever in the same neutropenic patient were included and counted as separate, independent NF events.

\section{Study measures and data collection}

Antimicrobial prophylaxis referred to any use of antibiotic and antifungal therapy within the 7 days prior to NF presentation. Blood cell counts, ANC, and inflammatory biomarkers of CRP and PCT at presentation, as indicated in patients' medical records, were collected. The outcome measures of fever as documented in the medical charts included data collection of microbiologically diagnosed bacterial and fungal infections (MDBIs and MDFIs), presence of predominant pathogens, whether modification of antibiotics was required during NF, medical complications in the first 3 and 5 days of an NF episode, total fever duration, and death. MDBIs and MDFIs were 
defined as infectious bacterial and fungal pathogen(s), respectively, detected in laboratory cultures. Medical complications included hypotension (systolic arterial pressure $<90 \mathrm{mmHg}$ ); arrhythmia; ICU admission due to septic shock; respiratory insufficiency, defined as oximetry saturation $<95 \%$ requiring oxygen therapy; documented altered mental status and acute kidney injury; and infiltrates on a chest radiograph [26].

\section{Statistical analysis}

To describe the sample demographics, clinical laboratory and microbiological data, and NF clinical outcome parameters, we used proportions, mean (M) and standard deviation (SD), or median (Med) and range, as appropriate. In categorizing data, the normal values for PCT and CRP were taken as $<0.5 \mathrm{ng} / \mathrm{mL}$ and $\leq 5 \mathrm{mg} / \mathrm{L}$ (i.e., $\leq 5 \mu \mathrm{g} / \mathrm{mL}$ ), respectively [27]. Proportions for the categorical variables were compared by Chi-squared test. Continuous data between the groups were compared by Mann-Whitney U test. A $p<0.05$ level of significance was used. Each NF episode was taken as an individual event in the analysis of data.

\section{Results}

\section{Patient demographic and clinical characteristics}

In the 5-year observational study, data included $282 \mathrm{NF}$ episodes from 133 patients with leukemias (Fig. 1). Table 1 summarizes the demographic and clinical characteristics of the sample. The mean age of the sample was 51.1 $(\mathrm{SD}=12.1)$, with $54.1 \%$ being male. AML was the most common underlying hematological malignancy, accounting for $76.2 \%(n=215)$ of NF episodes. In terms of antimicrobial prophylaxis prior to the onset of NF, 77.3\% (218 episodes) and 68.4\% (193 episodes) of cases had used antibiotic and antifungal prophylaxis, respectively. Over $66 \%$ (187 episodes) had used both antibiotic and antifungal prophylaxis, and $20.6 \%$ (58 episodes) had not undergone prophylactic antimicrobial therapy. Over two-thirds $(67 \%$, 189 episodes $)$ of the sample $(n=282)$ required antibiotic modifications after the first-line empirical antibiotic had been administered.

Among the parameters with abnormal ranges, the median values of CRP and PCT were $64.5 \mathrm{mg} / \mathrm{L}$ and $1.2 \mathrm{ng} / \mathrm{mL}$, respectively. The median duration of the NF was $124 \mathrm{~h}$ (5.2 days). There were 22\% (62 episodes) of MDBIs and $18.8 \%$ (53 episodes) of MDFIs. Gram-negative pathogens were slightly predominantly isolated $(12.8 \%, 36$ episodes) when compared with gram-positive pathogens (11.3\%, 32 episodes). The most common pathogens isolated were Escherichia coli (E. coli) $(7.1 \%, 20$ episodes) and

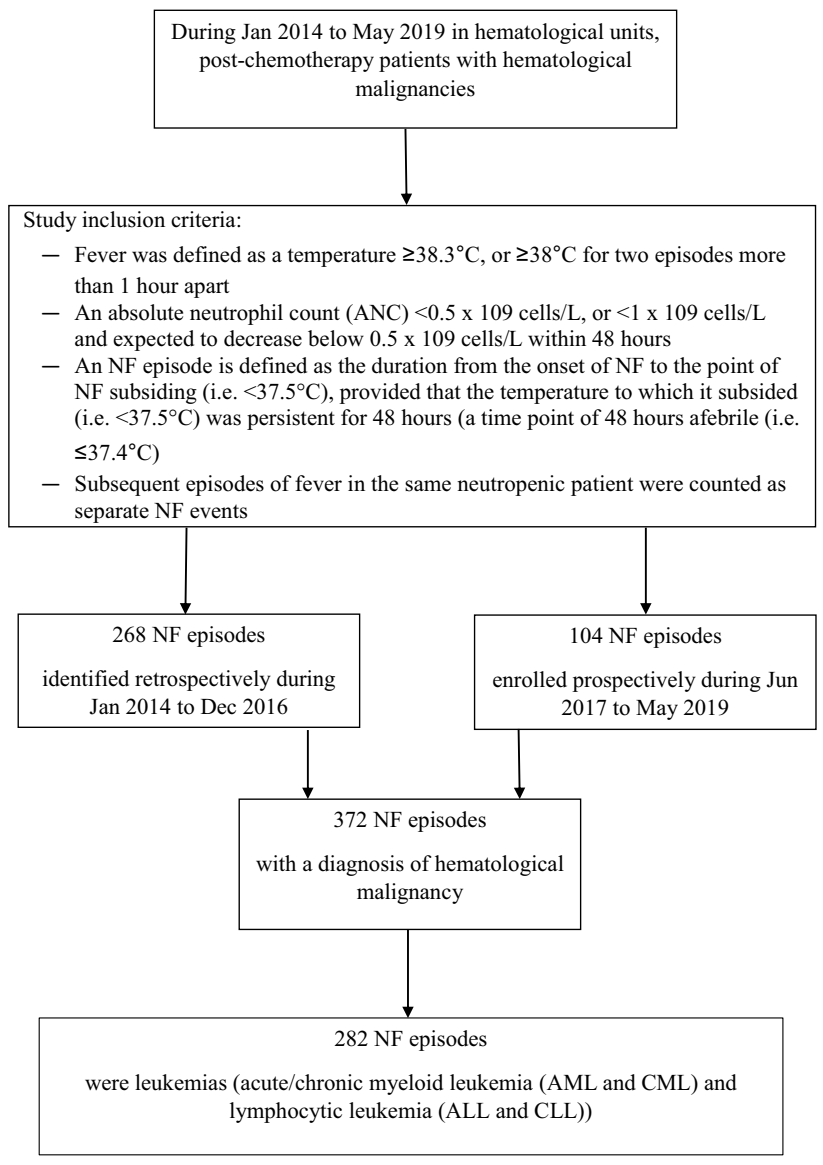

Fig. 1 Flow chart

methicillin-resistant Staphylococcus aureus (MRSA) (6.0\%, 17 episodes). In this sample $(n=133)$, totally 15 patients died (11.3\%). There were 13 deaths among those who had used antibiotic prophylaxis and 10 among those who had used antifungal prophylaxis. Documented abnormal chest $\mathrm{X}$-ray (infiltration/consolidation), hypotension, and impaired respiratory function were the major adverse medical complications of NF.

\section{Comparison of differences in outcome measures of fever and inflammatory biomarkers of CRP and PCT between those with and without antimicrobial prophylaxis}

Table 2 shows no statistically significant differences between MDBIs/MDFIs in those with and without antibiotic/antifungal prophylaxis, respectively. The presence of gram-negative and gram-positive pathogens was not significantly different between groups with and without prophylactic antibiotic treatment. There were no statistically significant differences for required antibiotic modification during NF in those with and without antibiotic prophylaxis, although higher proportions were found in those NF 
Table 1 Sample demographic and clinical characteristics ( $n=282$ NF episodes)

\begin{tabular}{|c|c|}
\hline Variables & Frequency $(\%)$ \\
\hline \multicolumn{2}{|l|}{ Gender } \\
\hline Male & 72 out of $133(54.1)$ \\
\hline Female & 61 out of $133(45.9)$ \\
\hline \multicolumn{2}{|l|}{ Hematological disorders } \\
\hline Acute myeloid leukemia (AML) & $215(76.2)$ \\
\hline Acute lymphocytic leukemia (ALL) & $52(18.4)$ \\
\hline Chronic myeloid leukemia (CML) & $6(2.1)$ \\
\hline Chronic lymphocytic leukemia (CLL) & $9(3.2)$ \\
\hline Microbiologically diagnosed bacterial infections (MDBIs) & $62(22.0)$ \\
\hline Microbiologically diagnosed fungal infections (MDFIs) & $53(18.8)$ \\
\hline \multicolumn{2}{|l|}{ Pathogens } \\
\hline Gram-negative bacterial pathogens & $36(12.8)$ \\
\hline Gram-positive bacterial pathogens & $32(11.3)$ \\
\hline Escherichia coli $($ E. coli $)$ & $20(7.1)$ \\
\hline Methicillin-resistant Staphylococcus aureus (MRSA) & $17(6.0)$ \\
\hline \multicolumn{2}{|l|}{ Prophylaxis before the onset of NF } \\
\hline Antibiotic & $218(77.3)$ \\
\hline Antifungal & $193(68.4)$ \\
\hline Antibiotic and antifungal & $187(66.3)$ \\
\hline No prophylaxis & $58(20.6)$ \\
\hline \multicolumn{2}{|l|}{ First-line empirical antibiotic at the onset of NF } \\
\hline Sulperazon (cefoperazone-sulbactam) & $137(48.6)$ \\
\hline Tazocin (piperacillin-tazobactam) & $90(31.9)$ \\
\hline With modification of antibiotic during FN & $189(67.0)$ \\
\hline \multicolumn{2}{|l|}{ Serious complications in the first 3 and 5 days of NF, during NF } \\
\hline Documented chest X-ray consolidation/infiltration & 40 (14.2), $53(18.8), 62(22.0)$ \\
\hline Hypotension & $36(12.8), 41(14.5), 56(19.9)$ \\
\hline Impaired respiratory function & $33(11.7), 37(13.1), 57(20.2)$ \\
\hline Severe bleeding requiring transfusion & $12(4.3), 12(4.3), 18(6.4)$ \\
\hline Arrhythmia & $9(3.2), 11(3.9), 15(5.3)$ \\
\hline Documented confusion/altered mental state & 7 (2.5), $10(3.5), 23(8.2)$ \\
\hline Required admission to intensive care unit & $5(1.8), 7(2.5), 9(3.2)$ \\
\hline Heart failure & $4(1.4), 5(1.8), 7(2.5)$ \\
\hline Disseminated intravascular coagulation & $3(1.1), 3(1.1), 3(1.1)$ \\
\hline Renal failure & $3(1.1), 3(1.1), 5(1.8)$ \\
\hline Deaths & 15 out of 133 patients $(11.3)$ \\
\hline AML & 14 \\
\hline CLL & 1 \\
\hline MDFIs & 6 \\
\hline MDBIs & 5 \\
\hline Gram-negative bacterial pathogens isolated & 2 \\
\hline Gram-positive bacterial pathogens isolated & 2 \\
\hline Gram-negative and gram-positive bacterial pathogens isolated & 1 \\
\hline With antibiotic prophylaxis & 13 \\
\hline With antifungal prophylaxis & 10 \\
\hline Variable (range) & Mean (SD), median \\
\hline Age (20-83 years) & $57.1(12.1), 58$ \\
\hline NF duration (3-993 h) & $180.0(178.1), 124$ \\
\hline ANC at the onset of NF $\left(0-0.9 \times 10^{9}\right.$ cells $\left./ \mathrm{L}\right)$ & $0.18(0.28), 0.0$ \\
\hline Hemoglobin level at the onset of NF $(1.7-11.8 \mathrm{~g} / \mathrm{dL})(n=218)$ & $7.8(1.5), 7.8$ \\
\hline Platelet count at the onset of NF $\left(2-221 \times 10^{9}\right.$ cells/L $)(n=212)$ & $28.8(37.7), 15$ \\
\hline
\end{tabular}


Table 1 (continued)

\begin{tabular}{ll}
\hline Variables & Frequency $(\%)$ \\
\hline Albumin level at the onset of NF $(13-96 \mathrm{~g} / \mathrm{L})(n=200)$ & $34.7(7.0), 35$ \\
Creatinine level at the onset of NF $(27-4725 \mu \mathrm{mol} / \mathrm{L})(n=205)$ & $91.1(326.0), 66$ \\
Bilirubin level at the onset of NF $(4-447 \mu \mathrm{mol} / \mathrm{L})(n=198)$ & $19.6(32.2), 15$ \\
CRP at the onset of NF $(0.9-270 \mathrm{mg} / \mathrm{L})(n=125)$ & $76.8(56.9), 64.0$ \\
$*$ CRP $>5 \mathrm{mg} / \mathrm{L}$ at the onset of NF $(6-270 \mathrm{mg} / \mathrm{L})(n=124)$ & $77.4(26.7), 64.5$ \\
PCT at the onset of NF $(0.0499-318 \mathrm{ng} / \mathrm{mL})(n=182)$ & $2.89(24.0), 0.18$ \\
$* *$ PCT $\geq 0.5 \mathrm{ng} / \mathrm{mL}$ at the onset of NF $(0.54-318 \mathrm{ng} / \mathrm{mL})(n=35)$ & $14.3(53.8), 1.20$ \\
\hline
\end{tabular}

$N F$ neutropenic fever; $n$ sample size; $S D$ standard deviation; $A N C$ absolute neutrophil count; $C R P$ C-reactive protein; $P C T$ procalcitonin; *abnormal values of CRP, when CRP normal reference value is $\leq 5 \mathrm{mg} / \mathrm{L}$; **abnormal values of PCT, when PCT normal reference value is $<0.5 \mathrm{ng} / \mathrm{mL}$

events with prophylaxis when compared with those without $(69.3 \%$ vs $59.4 \%, p=0.18)$. Regarding antimicrobial (i.e., antibiotic and antifungal) prophylactic treatments by adverse medical complications of hypotension, impaired respiratory function, and abnormal chest X-ray in the first 3 and 5 days of NF, the analyses of between-group differences were not significant, showing that fewer medical complications were found in NF events in patients using prophylaxis than in those who were not. In total, since outcome data with deaths and pathogen isolates such as MRSA, E. coli, and others was limited, we did not conduct between-group comparison analyses on these data.
Table 2 Antimicrobial prophylaxis by microbiologically diagnosed infections, antibiotic modification during NF, gramnegative pathogens, grampositive pathogens, and adverse medical complications during $\mathrm{NF}$

\begin{tabular}{|c|c|c|c|}
\hline & Antibiotic prophylaxis & & \\
\hline & Yes & No & \\
\hline Outcome measures of fever & $n(\%)$ & $n(\%)$ & $p$ values \\
\hline MDBIs & $47(21.6)$ & $15(23.4)$ & 0.88 \\
\hline Require modification of antibiotic during NF & $151(69.3)$ & $38(59.4)$ & 0.18 \\
\hline Presence of gram-negative pathogens & $29(13.3)$ & $7(10.9)$ & 0.78 \\
\hline Presence gram-positive pathogens & $22(10.1)$ & $10(15.6)$ & 0.32 \\
\hline \multicolumn{4}{|l|}{ Hypotension in the first } \\
\hline 3 days of $\mathrm{NF}$ & $26(11.9)$ & $10(15.6)$ & 0.57 \\
\hline 5 days of NF & $30(13.8)$ & $11(17.2)$ & 0.63 \\
\hline \multicolumn{4}{|l|}{ Impaired respiratory function in the first } \\
\hline 3 days of NF & $25(11.5)$ & $8(12.5)$ & 0.10 \\
\hline 5 days of $\mathrm{NF}$ & $26(11.9)$ & $11(17.2)$ & 0.38 \\
\hline \multicolumn{4}{|l|}{ Abnormal chest X-ray in the first } \\
\hline 3 days of NF & $32(14.7)$ & $8(12.5)$ & 0.81 \\
\hline \multirow[t]{4}{*}{5 days of NF } & $38(17.4)$ & $15(23.4)$ & 0.37 \\
\hline & Antifungal prophylaxis & & \\
\hline & Yes & No & \\
\hline & $n(\%)$ & $n(\%)$ & \\
\hline MDFIs & $36(18.7)$ & $17(19.1)$ & 1.00 \\
\hline \multicolumn{4}{|l|}{ Hypotension in the first } \\
\hline 3 days of NF & $24(12.4)$ & $12(13.5)$ & 0.96 \\
\hline 5 days of $\mathrm{NF}$ & $28(14.5)$ & $13(14.6)$ & 1.00 \\
\hline \multicolumn{4}{|l|}{ Impaired respiratory function in the first } \\
\hline 3 days of NF & $21(10.9)$ & $12(13.5)$ & 0.67 \\
\hline 5 days of NF & $22(11.4)$ & $15(16.9)$ & 0.28 \\
\hline \multicolumn{4}{|l|}{ Abnormal chest X-ray in the first } \\
\hline 3 days of NF & $26(13.5)$ & $14(15.7)$ & 0.75 \\
\hline 5 days of NF & $32(16.6)$ & $21(23.6)$ & 0.22 \\
\hline
\end{tabular}

$p$ Chi-square $p$ value significant at $<0.05 ; M D B I s$ microbiologically diagnosed bacterial infections; MDFIs microbiologically diagnosed fungal infections 
Table 3 Antimicrobial prophylaxis by NF duration, CRP, and PCT

\begin{tabular}{|c|c|c|c|c|}
\hline & NF duration (hours) & & & \\
\hline Treatments & Mean & SD & Median & $p$ values \\
\hline \multicolumn{5}{|c|}{ Antibiotics prophylactic } \\
\hline No $(n=64)$ & 183.9 & 185.7 & 109.5 & \multirow[t]{2}{*}{0.95} \\
\hline Yes $(n=218)$ & 178.9 & 176.3 & 124.5 & \\
\hline \multicolumn{5}{|c|}{ Antifungal prophylactic } \\
\hline No $(n=89)$ & 193.6 & 191.7 & 125 & \multirow[t]{4}{*}{0.39} \\
\hline \multirow[t]{3}{*}{ Yes $(n=193)$} & 173.7 & 171.6 & 124 & \\
\hline & \multicolumn{3}{|l|}{$\mathrm{CRP}>5(\mathrm{mg} / \mathrm{L})^{*}$} & \\
\hline & Mean & SD & Median & \\
\hline \multicolumn{5}{|c|}{ Antibiotics prophylactic } \\
\hline No $(n=35)$ & 78.9 & 72.4 & 53.0 & \multirow[t]{2}{*}{0.26} \\
\hline Yes $(n=89)$ & 76.9 & 49.7 & 69.0 & \\
\hline \multicolumn{5}{|c|}{ Antifungal prophylactic } \\
\hline No $(n=44)$ & 81.1 & 68.7 & 61.5 & \multirow[t]{4}{*}{0.65} \\
\hline \multirow[t]{3}{*}{ Yes $(n=80)$} & 75.4 & 49.3 & 67.0 & \\
\hline & \multicolumn{3}{|l|}{$\mathrm{PCT} \geq 0.5(\mathrm{ng} / \mathrm{mL})^{* *}$} & \\
\hline & Mean & SD & Median & \\
\hline \multicolumn{5}{|c|}{ Antibiotics prophylactic } \\
\hline No $(n=9)$ & 37.0 & 105.4 & 0.88 & \multirow[t]{2}{*}{0.34} \\
\hline Yes $(n=26)$ & 6.5 & 11.3 & 1.34 & \\
\hline \multicolumn{5}{|c|}{ Antifungal prophylactic } \\
\hline No $(n=13)$ & 27.0 & 87.5 & 1.06 & \multirow[t]{2}{*}{0.49} \\
\hline Yes $(n=22)$ & 6.8 & 12.1 & 1.34 & \\
\hline
\end{tabular}

$N F$ neutropenic fever; $S D$ standard deviation; $p$ Mann-Whitney U test $p$ value significant at $<0.05$; $C R P$ C-reactive protein; $P C T$ procalcitonin; *abnormal values of CRP, when CRP normal reference value is $\leq 5 \mathrm{mg} / \mathrm{L}$; **abnormal values of PCT, when PCT normal reference value is $<0.5 \mathrm{ng} / \mathrm{mL}$

Table 3 shows the results of antibiotic and antifungal prophylaxis by total fever duration, CRP, and PCT. Similarly, there were no statistically significant differences between fever duration, CRP, and PCT between those using and those not using prophylaxis. Although all between-group differences showed no statistical significance, higher median fever duration, CRP, and PTC values were found in NF events with prophylaxis than in those without.

\section{Discussion}

While considering leukemias as the target population under study, this research constitutes a considerable sample size of 282 post-chemotherapy NF events and adds to recent institutional findings with respect to previously scarce research on the effects of prophylactic antibiotic and antifungal treatments for post-chemotherapy NF in leukemias, primarily focused on the immediate outcome interests of NF. In terms of these outcome interests, CRP and PCT at the onset of fever, requiring antibiotic modification during NF, immediate adverse medical complications, the presence of gram-negative and gram-positive bacterial isolates, MDBIs, MDFIs, and the duration of NF, between-group analyses of those with and without prophylaxis analyses did not reveal significant differences. To some extent, the findings of this present institutional surveillance study might help to redefine the risk-benefit accounts of using antimicrobial prophylaxis, providing implications for service practice in the management of leukemias with chemotherapy.

In terms of the need for antibiotic modification after receiving first-line empirical antibiotic treatment, there were no significant differences between those who used and those who did not use prophylaxis. This might be interpreted as meaning that patients who underwent prophylactic treatments might not have exhibited a lesser pathogen load or experienced a significant benefit account from using prophylaxis in absolving second-line modified antibiotic treatments when compared with their counterparts who did not use prophylaxis. Investigators in previous research reported that patients who had received prophylactic antibiotics and developed NF had a significantly lower probability of response to the first-line empirical antibiotic [7]. Importantly and specifically, in our present study, NF events among those on antibiotic prophylaxis had higher CRP and PTC levels and a longer fever duration than in those who did not use prophylaxis, although between-group differences of these NF outcome measures were not significant. These group comparison findings might explain why patients who received prophylaxis had higher inflammatory biomarkers of CRP and PTC and might develop infections, requiring further modification of antibiotic treatments because of subsequent infections resistant to the first-line empirical antibiotic due to the use of/exposure to initial prophylaxis. Hence, patients might ultimately have fever for a longer time.

Our study findings, contrary to previous research [6, 7, 28], showed no significant between-group differences in microbiologically documented infections (MDBIs and MDFIs), inflammatory indicators of CRP and PTC, presence of gram-negative and gram-positive bacterial pathogens and the immediate medical complications of hypotension, impaired respiratory function, and abnormal chest $\mathrm{X}$-ray findings. In addition, antifungal prophylactic treatment might reduce the diagnostic sensitivity of the galactomannan enzyme immunoassay for fungal infection [19], and such prophylaxis may pose possible subsequent challenges to the choice of strategy during ongoing management of postchemotherapy neutropenia and NF; thus, researchers should remain cautious. Based on the above discussions, the benefit accounts of using antimicrobial prophylaxis appeared less supported.

The wider use of prophylactic antimicrobial treatments in the management of leukemias receiving chemotherapy has implications for service practice. Enhancing diagnostic 
laboratory surveillance on infection-related indicators and pathogen isolates and performing critical assessments of any adverse medical conditions (hypotension, impaired respiratory function, and chest infiltrations) during postchemotherapy neutropenia are promising in guiding and delivering a precise prescription of prophylactic antimicrobial treatments, although to date, critical implementation of such practices has been limited. Instead of broad use of antimicrobial prophylaxis in leukemias with post-chemotherapy neutropenia, it is possible that critical diagnostic and medical complication surveillance and periodic evaluation of regional susceptibility and resistance patterns of pathogens during post-chemotherapy neutropenia and NF are realistic in redefining the risk-benefit accounts of using prophylaxis over time, taking together the considerations of the following premises. With recent advances in pharmacological technology, chemotherapeutic agents may be more potent, with less immunosuppression, and this may enhance patients' immuno-protection against pathogens. In the era of microbial pandemics, ever-changing bacteriological patterns and the emergence of drug-resistant pathogens associated with the use of antimicrobial prophylaxis [8-11], health alertness, and self-awareness of healthcare precautions to minimize the risk of infection have been promoted at the individual level of the patient population. The toxicity of antimicrobial therapy and the emergence of antibiotic resistance associated with extensive use of prophylaxis have also been widely reported $[13,16]$. Importantly, there were no significant differences or benefits in the immediate outcomes of post-chemotherapy NF between those who had undergone prophylactic treatments and those who had not, as reported in our present study. Majority of deaths had undergone antibiotic (13 deaths) and antifungal (10 deaths) prophylactic treatments. Specifically, prophylactic use of quinolones remains under discussion, primarily pertaining to a higher risk for gram-positive infection and the development of resistance, including toward MRSA [28]. In our institution, which is using quinolones as prophylactic treatments, we noted that pathogen isolates by MRSA ( $n=17$, from a total of $282 \mathrm{NF}$ episodes) were higher when compared with data reported in a previous study $(n=5$, from a total of 1358 bloodstream infections) [28]. Gram-positive bacterial isolates $(n=32,11.3 \%)$ were slightly less predominant than gram-negative bacterial isolates $(n=36,12.8 \%)$, in contrast to previously reported data in which gram-negative bacterial isolates were markedly predominant [29-31].

There were several limitations in our study, including that the risk for unmeasured or unidentifiable confounding factors could have resulted in over- and under-estimation of the effects of antimicrobial prophylaxis. We could not exclude the possibility that residual confounding, such as by baseline comorbid illness and first and non-first chemotherapy cycles, might have influenced our analysis. Small frequency counts of the outcome data among group comparison analyses should be cautioned, although the sample sizes of these data were comparable with previous studies [7, 16, 28]. There were fewer characteristics and outcome data, such as MRSA and deaths, which limited the ability to conduct between-group comparisons.

\section{Conclusion}

Comparing group differences in terms of antimicrobial prophylaxis in post-chemotherapy NF in leukemias in our study did not show statistically significant differences in CRP and PCT at fever presentation, MDBIs, MDFIs, presence of gram-negative and gram-positive bacterial isolates, requiring modification of antibiotic treatments during NF, medical complications in the first 3 and 5 days of NF, or fever duration. Prophylactic antimicrobial treatment might not exhibit a lesser pathogen load and might result in subsequent infection that is resistant to the firstline empirical antibiotic due to the initial use of antibiotic prophylaxis during post-chemotherapy neutropenia. The benefit accounts of using prophylaxis are less supported. Use of antibiotic prophylaxis should be undertaken with caution due to a high risk of gram-positive infection and the development of resistance toward MRSA. Enhancing diagnostic laboratory surveillance and critical evaluation of adverse medical conditions during post-chemotherapy neutropenia and NF may provide insights to redefine the risk-benefit accounts of using antimicrobial prophylaxis.

Acknowledgements The authors give thanks to the Chief of Services, Dr. Law, the staff of the hematological unit, and the staff of the Medical Record Office for facilitating patient recruitment and medical record review and to Dr. PH Lee for giving statistical advice on this research. The authors are also grateful to Jackie Cheung, Isaac Cheng, Cindy Kwan, Sally Chan, Suki Ho, Lorelei Ip, and Carmen Ip for their assistance in data collection and to the patients whose participation made this research possible.

Authors' contributions CWC: conception and design of the study; supervised the conduct of the study, data collection, and analysis; and wrote the first draft of the manuscript. AM: contribution to design of the study, interpretation of data. HKKL: contribution to design of the study, interpretation of data. All authors: critical discussion and review of the manuscript and approval of the final manuscript.

Funding This research was supported by The Hong Kong Polytechnic University Block Grant (1-ZE81).

Data availability N/A

Code availability N/A 


\section{Declarations}

Ethics approval The study was approved by the ethics committees of the Hong Kong Polytechnic University, Hong Kong, and Kowloon West Cluster Hospital Authority, Hong Kong. All participants have provided written informed consent.

Consent to participate All participants have provided written informed consent.

\section{Consent for publication N/A}

Conflict of interest The authors declare no competing interests.

Open Access This article is licensed under a Creative Commons Attribution 4.0 International License, which permits use, sharing, adaptation, distribution and reproduction in any medium or format, as long as you give appropriate credit to the original author(s) and the source, provide a link to the Creative Commons licence, and indicate if changes were made. The images or other third party material in this article are included in the article's Creative Commons licence, unless indicated otherwise in a credit line to the material. If material is not included in the article's Creative Commons licence and your intended use is not permitted by statutory regulation or exceeds the permitted use, you will need to obtain permission directly from the copyright holder. To view a copy of this licence, visit http://creativecommons.org/licenses/by/4.0/.

\section{References}

1. Baden LR, Bensinger W, Angarone M, Casper C, Dubberke ER, Freifeld AG, Garzon R, Greene JN, Greer JP, Ito JI, Karp JE, Kaul DR, King E, Mackler E, Marr KA, Montoya JG, Morris-Engemann A, Pappas PG, Rolston K, Segal B, Seo SK, Swaminathan S, Naganuma M, Shead DA (2012) Prevention and treatment of cancer-related infections. J Natl Compr Canc Netw 10:1412-1445

2. Bucaneve G, Castagnola E, Viscoli C, Leibovici L, Menichetti F (2007) Quinolone prophylaxis for bacterial infections in afebrile high risk neutropenic patients. Eur J Cancer Suppl 5:5-12

3. de Naurois J, Novitzky-Basso I, Gill MJ, Marti FM, Cullen MH, Roila F (2010) Management of febrile neutropenia: ESMO Clinical Practice Guidelines. Ann Oncol 21(Suppl 5):v252-256

4. Flowers CR, Seidenfeld J, Bow EJ, Karten C, Gleason C, Hawley DK, Kuderer NM, Langston AA, Marr KA, Rolston KV, Ramsey SD (2013) Antimicrobial prophylaxis and outpatient management of fever and neutropenia in adults treated for malignancy: American Society of Clinical Oncology clinical practice guideline. J Clin Oncol Off J Am Soc Clin Oncol 31:794-810

5. Freifeld AG, Bow EJ, Sepkowitz KA, Boeckh MJ, Ito JI, Mullen CA, Raad II, Rolston KV, Young JA, Wingard JR (2011) Clinical practice guideline for the use of antimicrobial agents in neutropenic patients with cancer: 2010 update by the Infectious Diseases Society of America. Clin Infect Dis 52:e56-93

6. Gafter-Gvili A, Fraser A, Paul M, Vidal L, Lawrie TA, van de Wetering MD, Kremer LC, Leibovici L (2012) Antibiotic prophylaxis for bacterial infections in afebrile neutropenic patients following chemotherapy. Cochrane Database Syst Rev 1:CD004386

7. Eleutherakis-Papaiakovou E, Kostis E, Migkou M, Christoulas D, Terpos E, Gavriatopoulou M, Roussou M, Bournakis E, Kastritis E, Efstathiou E, Dimopoulos MA, Papadimitriou CA (2010) Prophylactic antibiotics for the prevention of neutropenic fever in patients undergoing autologous stem-cell transplantation: results of a single institution, randomized phase 2 trial. Am J Hematol $85: 863-867$

8. Colodner R, Rock W, Chazan B, Keller N, Guy N, Sakran W, Raz $\mathrm{R}$ (2004) Risk factors for the development of extended-spectrum beta-lactamase-producing bacteria in nonhospitalized patients. Eur J Clin Microbiol Infect Dis 23:163-167

9. Kanafani ZA, Mehio-Sibai A, Araj GF, Kanaan M, Kanj SS (2005) Epidemiology and risk factors for extended-spectrum $\beta$-lactamase-producing organisms: a case control study at a tertiary care center in Lebanon. Am J Infect Control 33:326-332

10. Lautenbach E, Patel JB, Bilker WB, Edelstein PH, Fishman NO (2001) Extended-spectrum $\beta$-lactamase-producing Escherichia coli and Klebsiella pneumoniae: risk factors for infection and impact of resistance on outcomes. Clin Infect Dis 32:1162-1171

11. Mendelson G, Hait V, Ben-Israel J, Gronich D, Granot E, Raz R (2005) Prevalence and risk factors of extended-spectrum betalactamase-producing Escherichia coli and Klebsiella pneumoniae in an Israeli long-term care facility. Eur J Clin Microbiol Infect Dis $24: 17-22$

12. Slavin MA, Lingaratnam S, Mileshkin L, Booth DL, Cain MJ, Ritchie DS, Wei A, Thursky KA (2011) Use of antibacterial prophylaxis for patients with neutropenia. Intern Med J 41:102-109

13. U.S. Food and Drug Administration (2016) FDA Drug Safety Communication: FDA updates warnings for oral and injectable fluoroquinolone antibiotics due to disabling side effects. Available from: http://www.fda.gov/Drugs/DrugSafety/ucm511530. $\mathrm{htm}$. Accessed on 29 Oct 2020

14. Bucaneve G, Micozzi A, Menichetti F, Martino P, Dionisi MS, Martinelli G, Allione B, D’Antonio D, Buelli M, Nosari AM, Cilloni D, Zuffa E, Cantaffa R, Specchia G, Amadori S, Fabbiano F, Deliliers GL, Lauria F, Foà R, Del Favero A (2005) Levofloxacin to prevent bacterial infection in patients with cancer and neutropenia. N Engl J Med 353:977-987

15. Leibovici L, Paul M, Cullen M, Bucaneve G, Gafter-Gvili A, Fraser A, Kern WV (2006) Antibiotic prophylaxis in neutropenic patients. Cancer 107:1743-1751

16. Mikulska M, Averbuch D, Tissot F, Cordonnier C, Akova M, Calandra T, Ceppi M, Bruzzi P, Viscoli C, EuropeanConference on Infections in L (2018) Fluoroquinolone prophylaxis in haematological cancer patients with neutropenia: ECIL critical appraisal of previous guidelines. J Infect 76:20-37

17. Villafuerte Gutierrez P, Villalon L, Losa J, Henriquez-Camacho C (2014) Treatment of febrile neutropenia and prophylaxis in hematologic malignancies: a critical review and update. Adv Hematol 2014:1-9

18. Pagano L, Caira M, Candoni A, Offidani M, Fianchi L, Martino B, Pastore D, Picardi M, Bonini A, Chierichini A, Fanci R, Caramatti C, Invernizzi R, Mattei D, Mitra ME, Melillo L, Aversa F, Van Lint MT, Falcucci P, Valentini CG, Girmenia C, Nosari A (2006) The epidemiology of fungal infections in patients with hematologic malignancies: the SEIFEM-2004 study. Haematologica 91:1068-1075

19. Marr KA, Laverdiere M, Gugel A, Leisenring W (2005) Antifungal therapy decreases sensitivity of the Aspergillus galactomannan enzyme immunoassay. Clin Infect Dis 40:1762-1769

20. Cordonnier C, Robin C, Alanio A, Bretagne S (2014) Antifungal pre-emptive strategy for high-risk neutropenic patients: why the story is still ongoing. Clin Microbiol Infect Off Publ Eur Soc Clin Microbiol Infect Dis 20(Suppl 6):27-35

21. Marston HD, Dixon DM, Knisely JM, Palmore TN, Fauci AS (2016) Antimicrobial resistance. JAMA 316:1193-1204

22. Juutilainen A, Hamalainen S, Pulkki K, Kuittinen T, Nousiainen T, Jantunen E, Koivula I (2011) Biomarkers for bacteremia and severe sepsis in hematological patients with neutropenic fever: 
multivariate logistic regression analysis and factor analysis. Leuk Lymphoma 52:2349-2355

23. Markova M, Brodska H, Malickova K, Valkova V, Cetkovsky P, Kolar M, Haluzik M (2013) Substantially elevated C-reactive protein (CRP), together with low levels of procalcitonin (PCT), contributes to diagnosis of fungal infection in immunocompromised patients. Support Care Cancer 21:2733-2742

24. Wu CW, Wu JY, Chen CK, Huang SL, Hsu SC, Lee MT, Chang SS, Lee CC (2015) Does procalcitonin, C-reactive protein, or interleukin- 6 test have a role in the diagnosis of severe infection in patients with febrile neutropenia? A systematic review and meta-analysis. Support Care Cancer 23:2863-2872

25. Hui EP, Leung LK, Poon TC, Mo F, Chan VT, Ma AT, Poon A, Hui EK, Mak SS, Lai M, Lei KI, Ma BB, Mok TS, Yeo W, Zee BC, Chan AT (2011) Prediction of outcome in cancer patients with febrile neutropenia: a prospective validation of the Multinational Association for Supportive Care in Cancer risk index in a Chinese population and comparison with the Talcott model and artificial neural network. Support Care Cancer 19:1625-1635

26. Klastersky J, Paesmans M, Rubenstein EB, Boyer M, Elting L, Feld R, Gallagher J, Herrstedt J, Rapoport B, Rolston K, Talcott J (2000) The multinational association for supportive care in cancer risk index: a multinational scoring system for identifying low-risk febrile neutropenic cancer patients. J Clin Oncol Off J Am Soc Clin Oncol 18:3038-3051

27. Uys A, Rapoport BL, Fickl H, Meyer PWA, Anderson R (2007) Prediction of outcome in cancer patients with febrile neutropenia: comparison of the multinational association of supportive care in cancer risk-index score with procalcitonin, C-reactive protein, serum amyloid A, and interleukins-1 $\beta,-6,-8$ and -10 . Eur J Cancer Care 16:475-483

28. Kern WV, Weber S, Dettenkofer M, Kaier K, Bertz H, Behnke M, Weisser M, Gotting T, Widmer AF, Theilacker C (2018) Impact of fluoroquinolone prophylaxis during neutropenia on bloodstream infection: data from a surveillance program in 8755 patients receiving high-dose chemotherapy for haematologic malignancies between 2009 and 2014. J Infect 77:68-74

29. Bhojaraja MV, Kanakalakshmi ST, Prabhu MM, Thomas J (2016) Clinical profile of high-risk febrile neutropenia in a tertiary care hospital. Australas Med J 09:142-151

30. Karanwal AB, Parikh BJ, Goswami P, Panchal HP, Parekh BB, Patel KB (2013) Review of clinical profile and bacterial spectrum and sensitivity patterns of pathogens in febrile neutropenic patients in hematological malignancies: a retrospective analysis from a single center. Indian J Med Paediatr Oncol 34:85-88

31. Taj M, Farzana T, Shah T, Maqsood S, Ahmed SS, Shamsi TS (2015) Clinical and microbiological profile of pathogens in febrile neutropenia in hematological malignancies: a single center prospective analysis. J Oncol 2015:5

Publisher's note Springer Nature remains neutral with regard to jurisdictional claims in published maps and institutional affiliations. 